Section Editor

Mitchell S.V. Elkind,

MD, MS

Antonella Macerollo, MD

Krisztina Róna-Vörös, MD

Walter Struhal, MD

Xenia Kobeleva, MD

Johann Sellner, MD

Correspondence to

Dr. Macerollo:

a.macerollo@ucl.ac.uk

Supplemental data at Neurology.org

International Issues:

\title{
An international survey of young neurologists' perceptions of future health care and neurology
}

The future occupations and interests of the medical profession have to be in some respects different from those of the past, and they have to be more various.

Medicine continues to evolve in response to our greater understanding of disorders and the discovery of new therapies. As the 21 st century begins, once again neurology finds itself in a pivotal evolutionary point of its eventful history. Breakthrough discoveries linked to molecular biology and genetic engineering have made personalized medicine foreseeable. ${ }^{2}$ Information technologies have paved the way for consultation of remote patients and have adapted to the educational demands of upcoming neurologists, patients, and caregivers. Moreover, there has been an increase in the percentage of women in the neurology workforce. ${ }^{3}$ Importantly, the voice of junior neurologists is increasingly recognized and incorporated in decision-making processes at the national and continental level. ${ }^{4}$

The spectrum of neurology has been ever changing and frontiers have to be regularly redefined. In some countries, subspecialties have been established to deal with different needs required by acute and chronic neurologic diseases. ${ }^{5}$ Demand and allocation of specialized doctors is likely to be defined by 3 interconnected developments: the aging population, the parallel rise in chronic disease, and the affordability of health care. Indeed, contemporary health care is barely managing to cover its costs and gaps in sufficient neurology service have become evident across Europe. ${ }^{6}$

There are limited data available on the current visions of neurologists for health care and neurology. It would be interesting to know whether the upcoming generation of neurologists is aware of global health care concerns. We aimed to garner ideas about current challenges and future development of health care among residents and junior neurologists from member states of the European
Union and neighboring countries. We further assessed emerging constraints for clinical practice as well as perceptions for the development of neurology subdisciplines and core competences.

METHODS Details on the Methods are in appendix e- 1 on the Neurology ${ }^{\circledR}$ Web site at Neurology.org. The questionnaire is provided in appendix e-2.

RESULTS Demographics. A total of 86 participants completed the survey, yielding a participation rate of $80 \%$. There were 45 in residency training (median 4.6 years [interquartile range (IQR) 1-12] since graduation from medical school) and 41 board-certified neurologists (for a median of 5.5 years [IQR 1-15]). The participants originated from the European Union or the European Economic Area (EEA) ( $\mathrm{n}=49$; countries: Bulgaria, Croatia, Denmark, Estonia, Germany, Greece, Hungary, Italy, Lithuania, Macedonia, Poland, Portugal, Romania, Slovenia, Spain, Turkey, United Kingdom) and Eastern Europe ( $\mathrm{n}=30$; countries: Armenia, Azerbaijan, Belarus, Bosnia and Herzegovina, Georgia, Moldova, Russia, Serbia, Ukraine). A minor group consisted of delegates from Africa and the Middle East ( $\mathrm{n}=7$; Egypt, Iraq, Nigeria, Tunisia). From each country, there were 1 to 4 participants, except for Romania $(\mathrm{n}=10)$ and Russia $(\mathrm{n}=14)$. The analysis of country of graduation and current workplace revealed that $95.2 \%$ had remained in their home country.

Current perception about health care and neurology. The analysis of the perception for the current status of health care revealed that the majority were content, as $11 \%$ were highly satisfied and 35\% somewhat satisfied (figure, A). On the other range of the scale, 30\% showed a level of discontent (somewhat, 27\%; highly, 3\%). There was a higher percentage of satisficed people among Africans/Middle Eastern and Eastern Europeans compared to European Union/EEA.

From the Sobell Department of Motor Neuroscience and Movement Disorders (A.M.), The National Hospital of Neurology and Neurosurgery, Institute of Neurology, University College London, UK; the Department of Neuroscience and Sense Organs (A.M.), Aldo Moro University of Bari, Italy; the Department of Neurology (K.R.-V.), Kecskemet County Hospital, Kecskemét, Hungary; the Department of Neurology (W.S.), Allgemeines Krankenhaus Linz, Austria; the Department of Neurology (X.K.), Medical School Hannover, Germany; the Department of Neurology (J.S.), Christian-Doppler-Klinik, Paracelsus Medical University, Salzburg, Austria; and the Department of Neurology (J.S.), Klinikum rechts der Isar, Technische Universität München, Germany.

Go to Neurology.org for full disclosures. Funding information and disclosures deemed relevant by the authors, if any, are provided at the end of the article. 
A

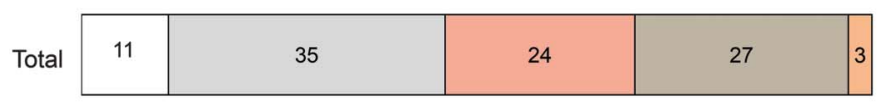

EU/EEA

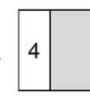

29

13

Europe Africa/
Middle East
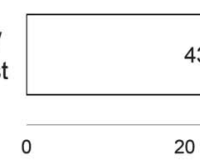

2040

$40 \quad 60$

$\%$ Participants
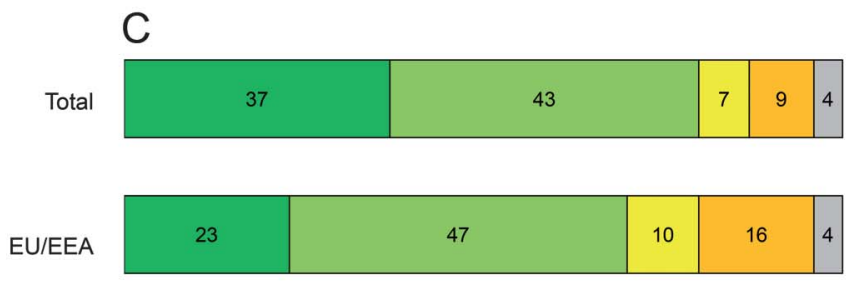

Eastern
Europe

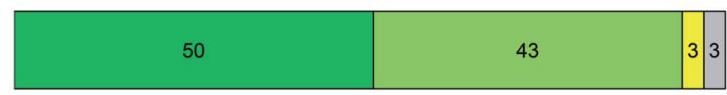

$$
\text { Africa/ }
$$
Middle East

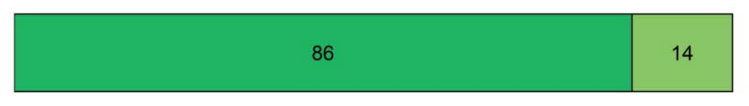

$$
0
$$

\section{D}

Total

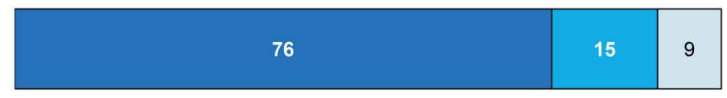

EU/EEA

Eastern Europe

Middle East
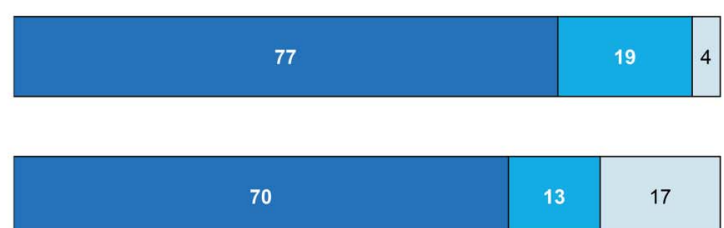

70

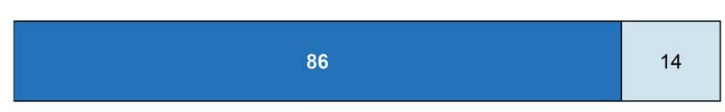
0

20

40

$\%$ Participants

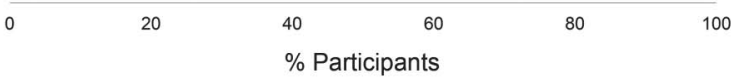

B
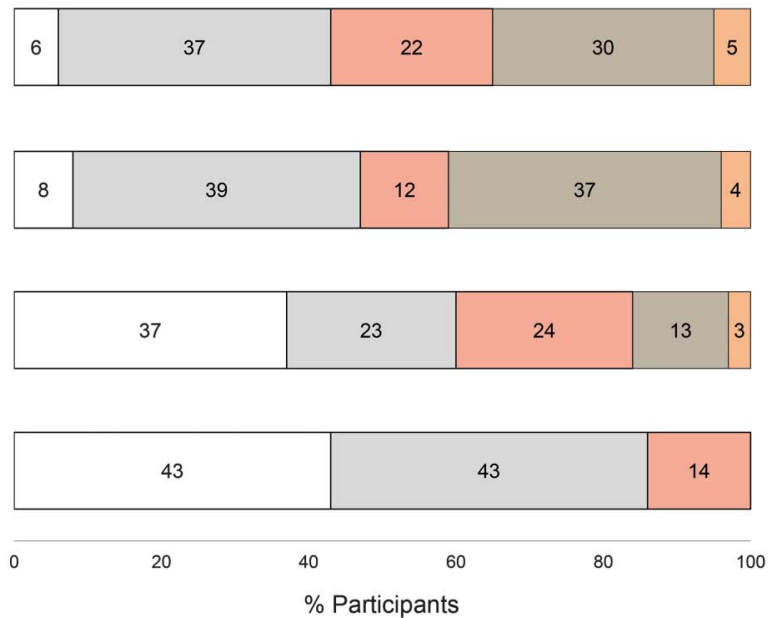

$\square$ Highly satisfied

$\square$ Somewhat satisfied

$\square$ Neutral

$\square$ Somewhat dissatisfied

- Highly dissatisfied

- Highly optimistic

$\square$ Somewhat optimistic

Neutral

$\square$ Somewhat pessimistic

$\square$ Highly pessimistic

$\square$ Yes

$\square$ No

口 I do not know

E

35

59

29

69
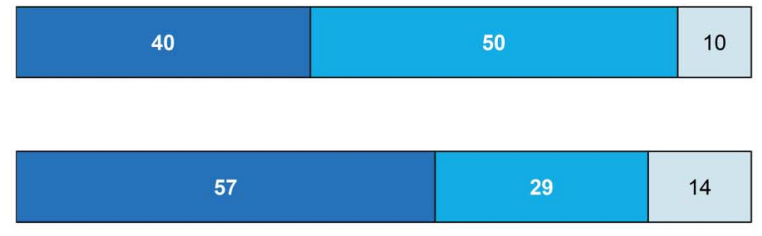

0

40

60

80

100

\% Participants

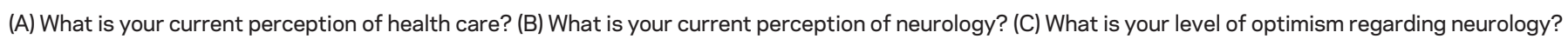

(D) In 10 years, will you be working as a neurologist? (E) In 10 years, will you be working in your home country? EEA = European Economic Area.

The current feeling of satisfaction specifically for neurology was again assessed on a 5-level ranking scale (figure, B). The percentage of satisfied participants was higher than ones who were dissatisfied ( $46 \%$ and $35 \%$, respectively), whereas $22 \%$ were neutral. The colleagues most satisfied with neurology in the home country came from Africa and the Middle East (43\%), followed by those from Eastern Europe (37\%). In contrast, only $8 \%$ from European Union/EEA reported high satisfaction. 
Level of optimism regarding the future of health care and neurology and reasons for skepticism for the future of medicine. An optimistic future of general health care was anticipated by $83 \%$. When asked about the future of neurology, $80 \%$ responded that they were optimistic (figure, C). The analysis of the demographic cohorts revealed a higher percentage of optimistic feeling for neurology among Africans and Middle Easterners (86\%). Lower optimism rates were present among participants from Eastern Europe and European Union/EEA (50\% and 47\%, respectively).

Regardless of the level of optimism, we analyzed potential factors related to demoralizing factors for the future of medicine. Three main factors were identified as reasons for skepticism: the expectation of a declining income and increasing living costs, distrust in the government, and the assumption that the revenue of the insurance would not be able to cover the increasing health care costs (table e-1). Analyzing the 3 demographic groups, we found differences for the European Union vs Eastern Europe vs Africa/Middle East (table e-1) for one to expect a progressive worsening of the health system (European Union/EEA, 43\%; Eastern Europe, 10\%; Africa/Middle East, 0\%). Moreover, there were differences towards increase of clinical workload and nonclinical workload, which were important reasons of skepticism for the European Union and Eastern Europe but not for Africa/Middle East (table e-1).

In 10 years, will you be working as a neurologist? Where? Seventy-six percent of respondents expect to practice as a neurologist in 10 years. This finding was homogenous among the 3 demographic groups (figure, D). Only 35\% estimated to remain in the originating country in 10 years. There was a higher rate among Africans/Middle Easterners (57\%; figure, E).

Emerging subspecialties for neurologists. Most frequently, aging and dementia (85\%), cerebrovascular disorders (82\%), cognitive neurology (74\%), neurodegenerative disorders (73\%), and multiple sclerosis (72\%) were considered to gain relevance in the future. There were no differences in the 3 subgroups (table e-2).

Key competences. Among the key competences gaining further relevance in the future were neuroimaging $(85 \%)$, neurogenetics $(84 \%)$, and laboratory examinations $(80 \%)$. We did not find differences in the 3 demographic groups (table e-3).

DISCUSSION The data presented are an effort to unveil the current visions of residents and young neurologists about the future of health care and neurology. The main finding was common optimism about health care as well as neurology. This enthusiasm is confirmed by the predominant plans to practice as a neurologist in 10 years. Interestingly, cross-border mobility might be considered, which corroborates the current interests in international relocation. The interest to relocate was prevailing and an increment of insufficient provision for neurologic service in certain areas can be anticipated. Hence, national bodies need to be aware of this mindset and counteract by raising the attractiveness for remaining in less attractive regions and countries.

Overall, young neurologists share the concerns of insufficient income and fear the subsequent impaired quality of life. The latter is viewed central in career decisions for the current generation of neurologists. ${ }^{7}$

Bradley $^{8}$ proposed a rise in the number of medical graduates entering neurology residency between 2000 and 2020. The estimation was supported by the explosion of knowledge in neuroscience and potential insights into previously unclear disorders. ${ }^{9}$ There were differences among the demographic cohorts. The level of optimism was particularly high in Africans/Middle Easterners.

Regardless of the level of optimism, we inquired for potential reasons leading to constraints. An expected worsening of the health system was more important for colleagues from the European Union/EEA (43\%) compared to Eastern Europe (10\%) and Africa/Middle East (0\%). Furthermore, there were differences in the expected consequences of the clinical and nonclinical workload, which were important reasons for skepticism in the European Union and Eastern Europe but not in Africa/Middle East.

The results of our survey highlighted that the upcoming generation of neurologists are aware of challenges related to demographic trends. The perception of subspecialties that will gain further importance included dementia, cerebrovascular diseases, cognitive neurology, and neurodegenerative diseases. Other relevant fields were movement disorders, sleep disorders, and multiple sclerosis, where bench to bedside approaches have been able to change diagnosis and treatment of disease over recent decades. Genebased therapies and stem cell technology are predicted to have rapid development to delay or repair the progression of brain degeneration disease, as well as deep brain stimulation devices to treat the most serious cases of movement disorders. ${ }^{8}$ The respondents of this survey did not indicate neuroinfectious diseases to gain importance in the future, although the WHO rates infectious diseases as major issue that will gain further importance within the next years. ${ }^{10}$ This may be related to the recent development in many European countries that other disciplines have taken over the care of patients with neuroinfections (e.g., internal medicine, critical care medicine).

We assume a couple of biases and limitations of this study. First, a selection bias is likely, as participants of this international neurology course were self-nominated and mainly originating from academic departments, and more updated on the progress and demands in the wide 
spectrum of neurologic subspecialties. This recruitment bias may also support the tendency to consider relocation.

Our survey confirms neurology in the 21 st century being a dynamic area of medicine, with constant advances and transitions.

Our data suggest that talented junior colleagues continue to be attracted to neurology and acknowledge ever-changing demands and upcoming challenges.

\section{AUTHOR CONTRIBUTIONS}

Antonella Macerollo: study concept and design, data acquisition and analysis, drafting of manuscript. Krisztina Róna-Vörös: study concept and design, data acquisition and analysis. Walter Struhal: study concept and design, data analysis, manuscript revision. Xenia Kobeleva: study concept and design, data acquisition and analysis. Johann Sellner: study concept and design, data acquisition and analysis, drafting of manuscript and revision.

\section{STUDY FUNDING}

No targeted funding reported.

\section{DISCLOSURE}

The authors report no disclosures relevant to the manuscript. Go to Neurology.org for full disclosures.

\section{REFERENCES}

1. Eliot CW. The future of medicine. Science 1906;24: 449-454.

2. Tyler K, York GK, Steinberg DA, et al. Part 2: history of 20th century neurology: decade by decade. Ann Neurol 2003;53(suppl 4):27-45.

3. Freeman WD, Vatz KA, Griggs RC, Pedley T. The Workforce Task Force report: clinical implications for neurology. Neurology 2013;81:479-486.

4. Rakusa M, Struhal W, Sellner J. The European Association of Young Neurologists and Trainees: the scent of freedom. Neurology 2014;82:536-539.

5. Compston A. Neurology: quo vadis? Clin Med 2011;11: 589-590.

6. Freeman WD, Vatz KA. The future of neurology. Neurol Clin 2010;28:537-561.

7. Biller J, Schneck MJ. The future of neurology. Front Neurol 2011;2:1.

8. Bradley WG. Neurology in the next two decades: report of the Workforce Task Force of the American Academy of Neurology. Neurology 2000;54:787-789.

9. Martin JB. The integration of neurology, psychiatry, and neuroscience in the 21st century. Am J Psychiatry 2002; 159:695-704.

10. Neurological disorders: public health approach. Chapter 3. In: Neurological Disorders: Public Health Challenges. Geneva: World Health Organization; 2006. 


\section{Neurology}

\section{International Issues: An international survey of young neurologists' perceptions of future health care and neurology}

Antonella Macerollo, Krisztina Róna-Vörös, Walter Struhal, et al.

Neurology 2015;84;e20-e23

DOI 10.1212/WNL.0000000000001180

This information is current as of January 26, 2015

\section{Updated Information \& Services}

Supplementary Material

\section{References}

Subspecialty Collections

Permissions \& Licensing

Reprints including high resolution figures, can be found at: http://n.neurology.org/content/84/4/e20.full

Supplementary material can be found at: http://n.neurology.org/content/suppl/2015/01/24/WNL.0000000000001 180.DC1

This article cites 9 articles, 5 of which you can access for free at: http://n.neurology.org/content/84/4/e20.full\#ref-list-1

This article, along with others on similar topics, appears in the following collection(s):

All Education

http://n.neurology.org/cgi/collection/all_education

Information about reproducing this article in parts (figures,tables) or in its entirety can be found online at:

http://www.neurology.org/about/about_the_journal\#permissions

Information about ordering reprints can be found online:

http://n.neurology.org/subscribers/advertise

Neurology ${ }^{\circledR}$ is the official journal of the American Academy of Neurology. Published continuously since 1951, it is now a weekly with 48 issues per year. Copyright @ 2015 American Academy of Neurology. All rights reserved. Print ISSN: 0028-3878. Online ISSN: 1526-632X.

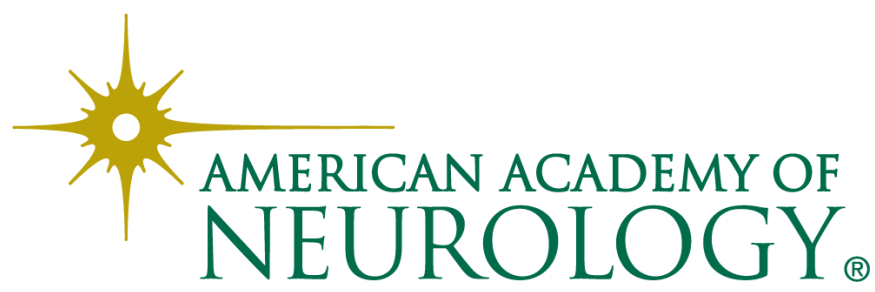

